\title{
EFFECTS OF SKIN THICKNESS AND CORE DENSITY ON THE RESIDUAL DENT DEPTH IN AEROSPACE SANDWICH PANELS
}

\author{
D. WOWK ${ }^{1} \&$ C. MARSDEN ${ }^{2}$ \\ ${ }^{1}$ The Royal Military College of Canada, Kingston, Canada. \\ ${ }^{2}$ Concordia University, Montreal, Canada.
}

\begin{abstract}
Sandwich panels are commonly used for aerospace structures that require a high-bending stiffness, but the thin facesheets that are bonded to the core can be susceptible to impact damage. It is necessary to be able to identify and assess the severity of the damage, but this can be difficult when dents are not visible on the surface of the skin. This can occur when the dent elastically springs back immediately after impact, and can cause the skin to return close to its original position, leaving little indication that a damaged core exists. Identifying combinations of skin thickness and core density that are more susceptible to spring back can enable better decisions to be made with respect to inspection procedures. Finite element simulations of metal-skinned honeycomb panels indicate that more spring back is expected to occur from panels composed of thicker skins and lower density core.

Keywords: core crush, finite element analysis, honeycomb, impact simulation, residual dent, sandwich panel, spring back.
\end{abstract}

\section{INTRODUCTION}

In the aerospace industry, honeycomb sandwich panels are often used for components that require high bending-stiffness to weight ratios such as floor panels and flight control surfaces. However, the thin skins make these panels susceptible to damage due to impact events such as tool drops and hail storms. In many instances, the location of damage can be identified visually when the dent is large or penetration of the skin has occurred, and repair or panel replacement can be performed. One of the more challenging modes of damage to detect is when the honeycomb core has been crushed, but the damage is not clearly visible on the skin (barely visible impact damage -BVID). This occurs when the skin elastically springs back immediately after impact, making the surface dent difficult to detect during a visual inspection. Even though the damage may not appear to be significant based on the surface indications, extensive core crush may still be present which could affect the structural integrity of the panel. Tomblin et al. [1] have experimentally demonstrated that this damage mode can result due to impact from larger diameter indenters. Visual inspection may therefore be an unreliable tool for assessing the extent of damage in sandwich panels that experience significant amounts of spring back. The present study focuses on identifying sandwich panel configurations that are more likely to undergo significant spring back, which could help to identify panels that should be examined using detection methods other than visual inspections.

Numerous studies in the literature have focused on the use of finite element simulations for predicting the impact resistance and energy absorption of honeycomb sandwich panels. 
These simulations often focus on the material properties and failure models that are necessary for accurately predicting the force-displacement response during panel impact [2-5]. Other studies have focused on simulating the crushing mechanism of the honeycomb in order to predict the compressive strength of the core [6-10]. The most common parameters that have been examined deal with the effect that impact energy and indenter diameter has on sandwich panel damage and the relationship between impact force and indentation depth. Less focus has been placed on the panel configuration and the effects that facesheet thickness and core density have on residual damage.

The experimental work by Tomblin et al. [1] has shown that the residual damage area and depth of the deformed skin can be significantly less than for the crushed core because of elastic spring back. It is therefore necessary to include spring back in finite element simulations that predict residual damage. Lacy et al. [11] incorporated the effects of spring back into the initial damage state of dented panels in order to more accurately predict residual strength. Residual dent geometry due to spring back has been predicted by Aminanda et al. [12], again with the purpose of predicting residual panel strength. In the present study, spring back is included in dynamic simulations of a low-velocity impact between a spherical indenter and a sandwich coupon with 7075-T6 skins and 5056-H39 aluminum core. The skin thickness, cell wall thickness and cell size were all varied, and their effects on the residual dent depth and the magnitude of spring back were examined.

\section{METHODOLOGY}

Virtual testing of a spherical indenter impacting a 2.5"x2.5" 1 " sandwich coupon with 7075-T6 skins and 5056-H39 aluminum core was performed using an explicit dynamic finite element code (AUTODYN). Inertial effects, material plasticity, contact, large deformation and element failure strain were all incorporated, and the honeycomb core was represented at the cellular level. Each coupon was impacted to a prescribed depth and then allowed to elastically spring back to form a residual dent.

The finite element simulation was composed of three components; the indenter, the skin and the core as shown in Fig. 1. The steel indenter was assumed to be a rigid body, and have a spherical impact surface with a radius of 0.75 " and a weight of $2.2 \mathrm{lbs}$. A linear elastic material model was used with the properties shown in Table 1. The skin and the walls of the honeycomb core were modeled as planar surfaces with a prescribed thickness. The ribbon

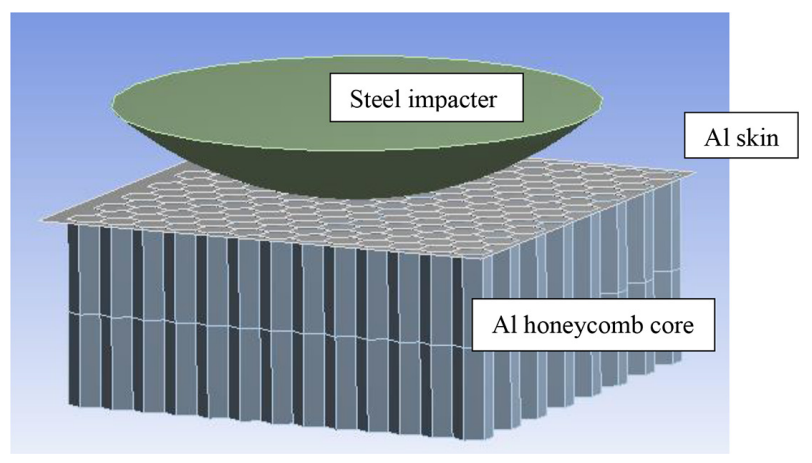

Figure 1: The three components of the sandwich panel impact models. 
Table 1: Material properties used for the indenter, skin and core.

\begin{tabular}{llllll}
\hline & E(ksi) & $\begin{array}{l}\text { Poisson's } \\
\text { Ratio }\end{array}$ & $\begin{array}{l}\text { Yield } \\
\text { (psi) }\end{array}$ & $\begin{array}{l}\text { Tangent } \\
\text { Modulus (ksi) }\end{array}$ & $\begin{array}{l}\text { Failure } \\
\text { Strain }\end{array}$ \\
\hline Indenter (steel) & 29,000 & 0.3 & - & - & - \\
Skin (7075-T6) & 10,400 & 0.33 & 73 & 72.5 & 0.11 \\
Core (5056-H39) & 10,300 & 0.33 & 50 & 72.5 & 0.15 \\
\hline
\end{tabular}

direction of the honeycomb core was represented by specifying the cell wall thickness in the longitudinal direction to be twice as large as the angled walls of the hexagonal cells. The skin was made from 7075-T6 and was attached to the core using common nodes to represent an adhesive connection. The core and skin were assumed to remain attached throughout the simulation. The skin used a bilinear material plasticity model with a yield stress of $73 \mathrm{ksi}$ and a tangent modulus of $72.5 \mathrm{ksi}$. The core also used a bilinear material plasticity model with a yield stress of 50ksi and a tangent modulus of $72.5 \mathrm{ksi}$. Plastic failure strains of $11 \%$ and $15 \%$ were defined for the skin and the core respectively after which elements would be eroded, representing material failure. All material values used are shown in Table 1. Material strain rate sensitivity was not included in this model due to the relatively low impact velocity.

Planar, quadrilateral elements were used to mesh the core and the skin and solid elements were used for the indenter. The elements were concentrated in the impact region and the top half of the core, with four elements being used across each cell wall. Further mesh studies are required to determine the optimal element size as previous work performed by Aktay et al. [6] has demonstrated that progressive failure in the core is mesh dependent and smaller elements do not necessarily produce more realistic predictions. In their study using Nomex core, three elements across the cell walls produced more realistic predictions of core crush than six elements across the cells walls. Contact was defined between the indenter and the skin, as well as between the skin and the core. Self-contact was also defined for the cell walls of the core. The lower surface of the core was defined to be fixed in all displacements and rotations, and the indenter was constrained to move only in the vertical direction. A prescribed displacement of 0.08 " applied over a time of $0.0005 \mathrm{~s}$ was defined for the indenter to control the maximum impact depth. This corresponded to an impact velocity representing a 33" drop height.

The baseline configuration of the sandwich panel had a skin thickness of 0.012 ", a cell wall thickness of 0.001 ", a cell size of 0.1875 " and a maximum impact depth of 0.066 ". The maximum impact depth and the prescribed displacement differ by the initial gap that was present between the indenter and the top surface of the skin. This impact depth was chosen to produce a damage mode consisting of core crush and plasticity in the skin. Simulations involving three different parameters were completed according to the specifications listed below. Each study started with the baseline case which is indicated in bold, and then parameters were varied independently from each other.

- Skin thickness (0.008", 0.012", 0.025", 0.032", 0.04", 0.05”, 0.063", 0.071", 0.08”)

- Cell size (0.125", 0.156", 0.1875", 0.25", 0.375")

- Cell wall thickness (0.001", 0.0015”, 0.0025", 0.0035", 0.004”) 


\section{RESULTS}

\subsection{Damage development}

The process of how the residual dent forms can be described in following stages and is illustrated in Fig. 2.

- The impacter contacts the skin and the skin bends. The cell walls under the impact site compress and then locally bend (Fig. 2a).

- The bend in the cells walls deepens, leading to local failure of the cell walls at a constant depth below the skin (Fig. 2b).

- After the maximum impact depth has been reached and the impacter has rebounded, the system of skin and the attached core are allowed to relax. Since the skin is less damaged,

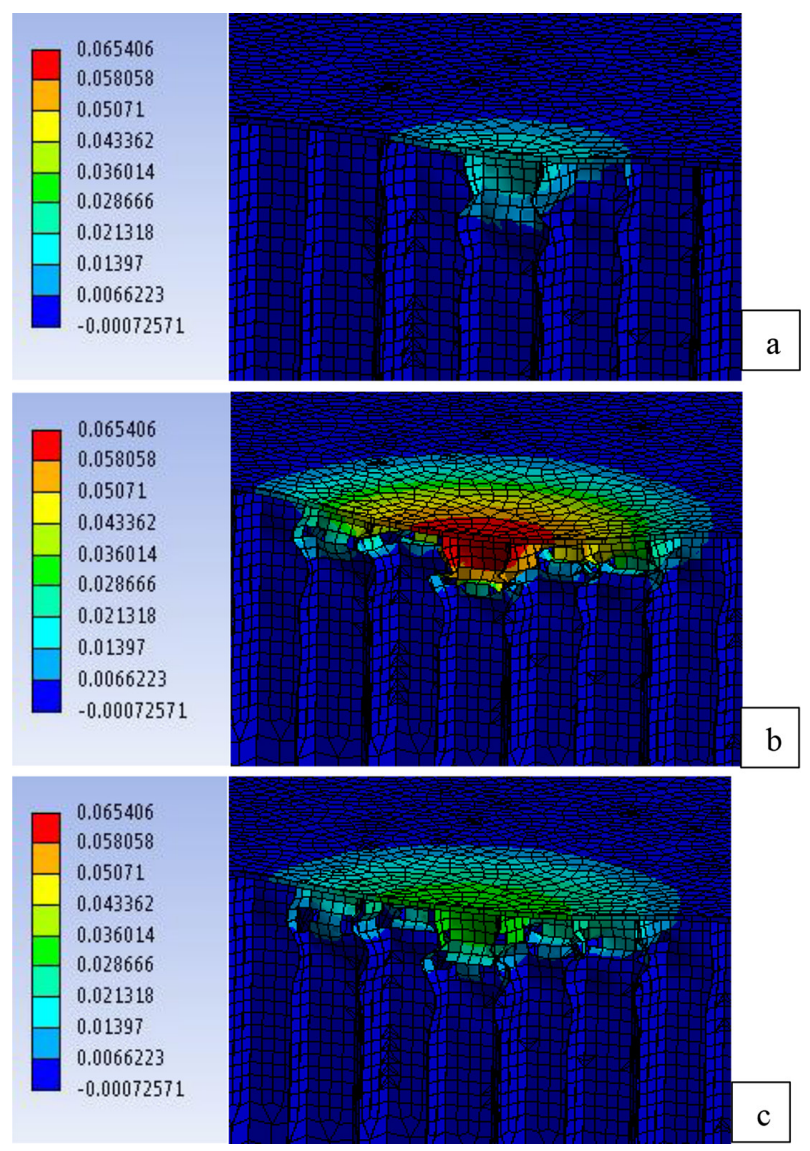

Figure 2: Stages in residual dent development shown on a cross-section through the dent with the indenter hidden from view. (a) initial contact between the indenter and the skin, (b) point of maximum deformation (c) residual dent. The contour bars indicate vertical displacement (inches). 


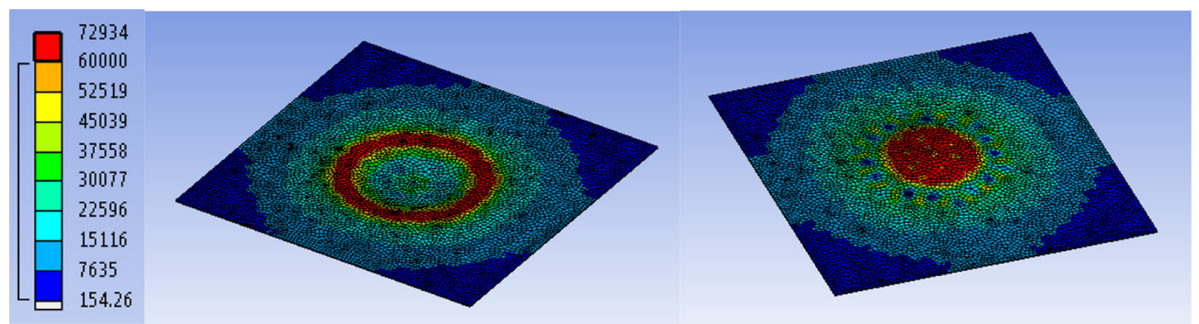

Figure 3: Left) the Von Mises stress distribution (psi) on the top of the 0.012" skin. Right) the Von Mises stress distribution on the bottom of the 0.012 " skin. The results are taken at the time of maximum impact depth.

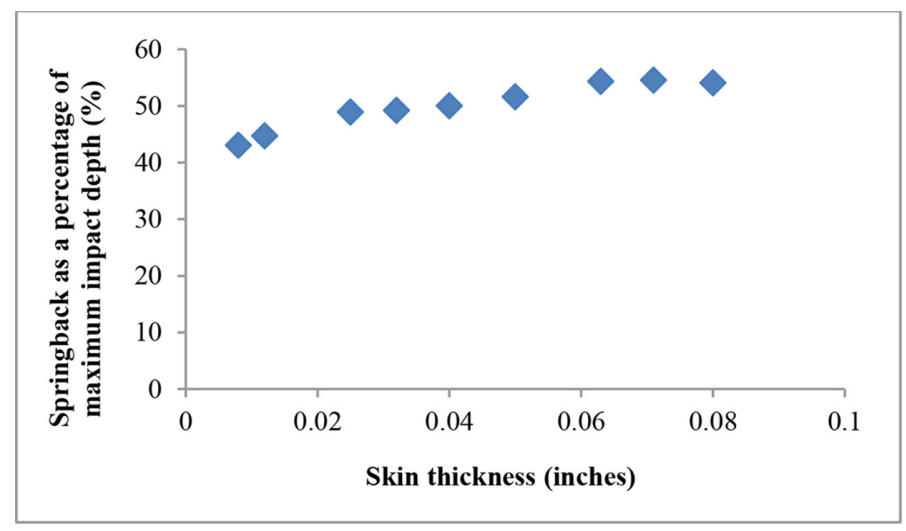

Figure 4: The magnitude of spring back for different skin thicknesses, measured as a percentage of the maximum impact depth. A cell wall thickness of 0.001 " and a cell size of 0.1875 " were used.

it has the ability to spring back more than the core. An equilibrium position is reached between the skin and the core, resulting in the residual dent (Fig. 2c).

- As the skin springs back it pulls the damaged core with it, imposing a residual tensile load on the core.

The resulting Von Mises stress distribution in the skin differs between the top and bottom surfaces as shown in Fig. 3. The top of the skin (impact surface) sees higher stresses around the edge of the dent where it is supported by the intact core. The bottom of the skin sees higher stresses at the centre of the dent where the deformation is the greatest. The largest stresses occur in the regions where there are high tensile stresses.

\subsection{Effect of skin thickness and core density on residual dent depth}

Predictions from this study show that the thickness of the skin has the largest effect on residual dent depth, with Fig. 4 indicating that panels with thicker skins undergo more spring back. The panel with a 0.08 " thick skin springs back 54\% from its maximum impact depth, and results in a residual dent depth that is $23 \%$ smaller than the 0.008 " skin. The final dent 


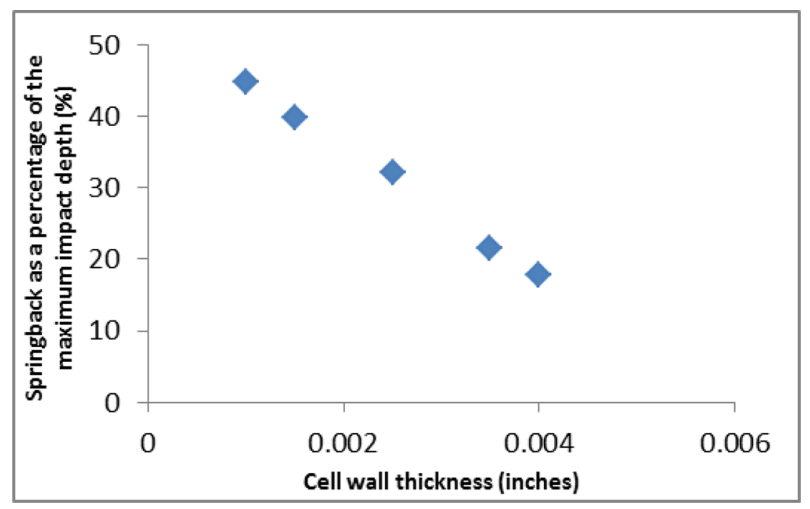

Figure 5: The magnitude of spring back decreases with increasing cell wall thickness. A skin thickness of 0.012 " and a cell size of 0.1875 " was used.

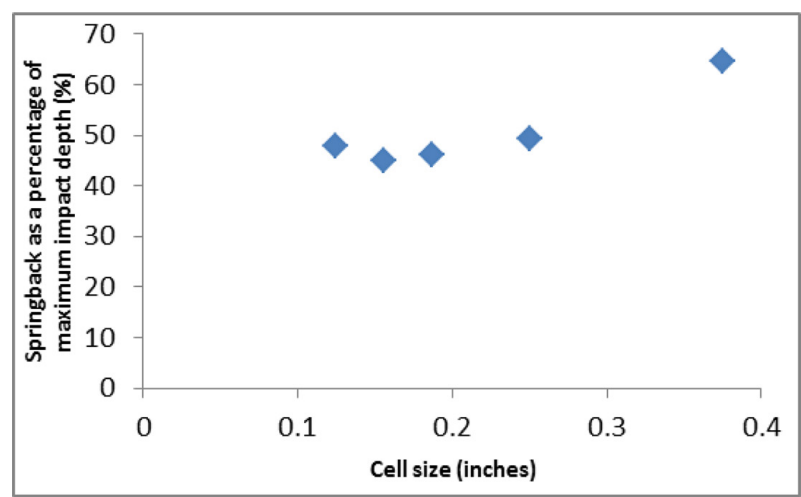

Figure 6: The magnitude of spring back increases with increasing cell size. A skin thickness of 0.012 " and a cell wall thickness of 0.001 " was used.

depths for the 0.008 " and 0.08 " skins are 0.037 " and 0.031 ", respectively, with all the residual dents being within the BVID limit and therefore not readily detected visually. The difference in residual dent depth occurs primarily because of the difference in the size of the damage region and will be discussed further in section 4 . Thicker skins spread the load over a larger area causing a larger damage region and more spring back.

For a given maximum impact depth, cores with larger cell sizes and smaller wall thickness allowed more spring back to occur as seen in Figs 5 and 6 . The lower density core is more easily deformed, and the damage area is larger than for the denser core. Larger damage regions are more capable of spring back, resulting in a shallower residual dent. Note that as the cell size was changed, the location of the cells with respect to the impacter also changed. This can have an effect on the amount of spring back depending on whether the skin under the impacter is in the centre of a cell or attached to a cell wall. 


\section{DISCUSSION}

The amount of spring back that occurs is due to a combination of the stiffness of the skin, the stiffness of the core and the size of the damaged region. In thinner skins, the core damage is contained to a region directly under the indenter, while in thicker skins the damage extends over a larger area. Figure 7 illustrates how the overall dent profile changes with skin thickness. Thinner skins conform to the shape of the indenter, while thicker skins can distribute the impact force over a larger area resulting in dents with less curvature. The linear relationship

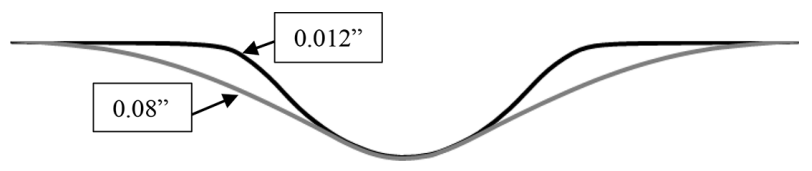

Figure 7: Illustration of the dent profile for a skin thickness of 0.012" and 0.08". Thicker skins produce dents with less curvature.

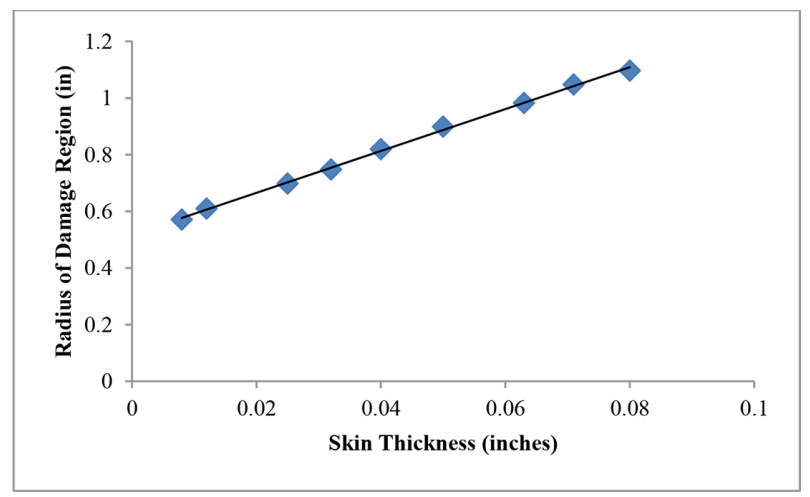

Figure 8: The radius of the damage region on the skin surface at the time of maximum impact depth. A cell wall thickness of 0.001 " and a cell size of 0.1875 " was used.

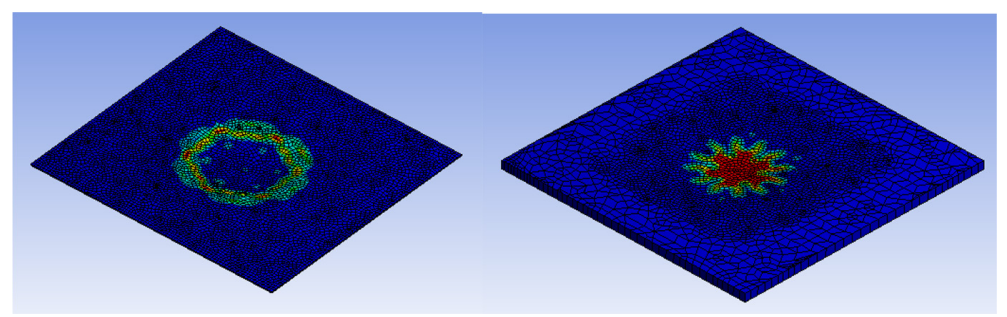

Figure 9: Left) equivalent plastic strain distribution on the top of the 0.012" skin. Right) equivalent plastic strain distribution on the top of the 0.08 " skin. Red shows regions of larger plastic strain and blue indicates the skin is still elastic. These images are taken at the time of maximum impact depth. 
between the radius of the damage region, and the skin thickness can be seen in Fig. 8 with the 0.08 " thick skin having a damage radius that is 1.9 times larger than the 0.008 " skin.

The difference in the size and shape of the dent profile leads to skins of different thicknesses yielding in different locations. These regions of plasticity cause permanent deformation in the skin and during spring back, the residual dent shape must conform to the permanent deformation already present. For thinner skins, the high curvature at the edge of the dent causes yielding where the skin is supported by the intact core as seen in Fig. 9a). The permanent curvature at the edge of the dent makes it more difficult for spring back to occur. In the thicker skins, the gradual curvature of the dent results in the plastic region being at the centre of the dent as shown in Fig. 9b). The residual dent shape can more easily accommodate permanent deformation at the centre of the dent, thus enabling more spring back to occur. A similar effect is seen between the density of the core, the shape of the dent profile and the amount of spring back. As the density of the core increases, the damage area becomes smaller resulting in less spring back.

\section{CONCLUSIONS AND RECOMMENDATIONS}

The results of these studies indicate that sandwich panels with a lower core density and thicker skins are the most susceptible to BVID with crushed core underneath the skin. In addition, the radius of the damage area increases linearly with skin thickness, and the location of the highest stresses moves from the edge of the dent in thinner skins to the centre of the dent for thicker skins. In thicker skins, the dents are also harder to visually detect because the transition in curvature between the dented and undented regions of the skin is more gradual than for thinner skins. These trends could be used to help identify sandwich panels that should be inspected using techniques other than visual inspections.

As with all numerical simulations, physical testing is required to validate the modeling methods and the predicted results presented here. Additional simulations incorporating the combined effects of facesheet thickness, core density and impact depth will help to identify a wider range of cases where BVID is most likely to occur.

\section{REFERENCES}

[1] Tomblin, J.S., Raju, K.S., Liew, J. \& Smith, B.L., Impact damage characterization and damage tolerance of composite sandwich airframe structures. Final Report, Federal aviation administration report number DOT/FAA/AR-00/44, 2001.

[2] Manes, A., Gilioli, A., Sbarufatti, C. \& Giglio, M., Experimental and numerical investigations of low velocity impact on sandwich panels. Composite Structures, 99, pp. 8-18, 2013. http://dx.doi.org/10.1016/j.compstruct.2012.11.031

[3] Menna, C., Zinno, A., Asprone, D. \& Prota, A., Numerical assessment of the impact behaviour of honeycomb sandwich structures. Composite Structures, 106, pp. 326-339, 2013. http://dx.doi.org/10.1016/j.compstruct.2013.06.010

[4] Castanie, B., Bouvet, C., Aminanda, Y., Barrau, J.-J. \& Thevenet, P., Modelling of lowenergy/low-velocity impact on Nomex honeycomb sandwich structures with metallic skins. International Journal of Impact Engineering, 35, pp. 620-634, 2008. http://dx.doi.org/10.1016/j.ijimpeng.2007.02.008

[5] Aktay, L., Johnson, A.F. \& Holzapfel, M., Prediction of impact damage on sandwich composite panels. Computational Materials Science, 32, pp. 252-260, 2005. 
http://dx.doi.org/10.1016/j.commatsci.2004.09.044

[6] Aktay, L., Johnson, A.F. \& Kroplin, B.-H., Numerical modeling of honeycomb core crush behaviour. Engineering Fracture Mechanics, 75, pp. 2616-2630, 2008. http://dx.doi.org/10.1016/j.engfracmech.2007.03.008

[7] Heimbs, S., Virtual testing of sandwich core structures using dynamic finite element simulations. Computational Materials Science, 45, pp. 205-216, 2009. http://dx.doi.org/10.1016/j.commatsci.2008.09.017

[8] Giglio, M., Manes, A. \& Gilioli, A., Investigations on sandwich core properties through an experimental-numerical approach. Composites: Part B, 43, pp. 361-374, 2012. http://dx.doi.org/10.1016/j.compositesb.2011.08.016

[9] Yamashita, M. \& Gotoh, M., Impact behaviour of honeycomb structures with various cell specifications - numerical simulation and experiment. International Journal of Impact Engineering, 32, pp. 618-630, 2005. http://dx.doi.org/10.1016/j.ijimpeng.2004.09.001

[10] Aminanda, Y., Castanie, B., Barrau, J.-J. \& Thevenet P., Experimental analysis and modelling of the crushing of honeycomb cores. Applied Composite Materials, 12, pp. 213-227, 2005. http://dx.doi.org/10.1007/s10443-005-1125-3

[11] Lacy, T.E. \& Hwang, Y., Numerical modeling of impact-damaged sandwich composites subjected to compression-after-impact loading. Composite Structures, 61, pp. 115-128, 2003. http://dx.doi.org/10.1016/S0263-8223(03)00034-5

[12] Aminanda, Y., Castanie, B., Barrau, J.-J. \& Thevenet P., Experimental and numerical study of compression after impact of sandwich structures with metallic skins. Composites Science and Technology, 69, pp. 50-59, 2009. http://dx.doi.org/10.1016/j.compscitech.2007.10.045 